Sharif University of Technology
Scientia Iranica
SCIENTIA
I RAN ICA
http://scientiairanica.sharif.edu

\title{
Assessment of MIDA method for mid-rise steel structures with non-symmetrical plan
}

\author{
M. Zanjanchi and M. Mofid* \\ Department of Civil Engineering, Sharif University of Technology, Tehran, Iran.
}

Received 24 May 2017; received in revised form 9 May 2018; accepted 11 March 2019

\section{KEYWORDS}

Modal incremental dynamic;

Incremental dynamic analysis;

Asymmetric-plan

building;

Unconventional plan;

Seismic demand.

\begin{abstract}
Determination of nonlinear dynamic behavior of structures has always been one of the main goals of both structural and earthquake engineers. One of the newest methods for analyzing seismic behavior of structures is Modal Incremental Dynamic Analysis (MIDA). In fact, this method is an alternative to the Incremental Dynamic Analysis (IDA), which is a difficult and time-consuming method. Despite the MIDA's approximate results, advantages such as adequate accuracy, high speed, and low cost make this method an efficient and appropriate approach. In all the previous studies, the proposed models have had a regularized plan; hence, all the analyses have been carried out on a frame. In this study, the MIDA analysis was developed in an asymmetric-plan-type building by considering three structures with 4, 7, and 10 stories having irregularity in plan. Accuracy of the work was examined. Also, through a simplification, instead of considering an unconventional plan, we used a rectangular plan with an eccentricity of $15 \%$ between the center of mass and the center of rigidity. Comparing the results of this study and the IDA method proved the high level of accuracy of this method in assessing seismic demands.
\end{abstract}

(C) 2019 Sharif University of Technology. All rights reserved.

\section{Introduction}

Accurate estimation of seismic demand and capacity of structures is the main basis of Performance-Based Earthquake Engineering (PBEE). However, several methods are being proposed for investigation. Explicit attention to the inelastic behavior of structures is required for estimating the seismic demands at low performance levels such as life safety and collapse prevention. Nonlinear static processes are utilized as a part of the conventional performance evaluation of structural engineering, although Non-Linear Response

\footnotetext{
*. Corresponding author. Tel.: +982166014828; Fax: +982166014828

E-mail addresses: moeinzanjanchi@alum.sharif.edu ( $M$. Zanjanchi); mofid@sharif.edu(M. Mofid)
}

doi: $10.24200 /$ sci. 2019.21356
Time History Analysis (NL-RHA) is one of the most precise methods for seismic demand computations.

Many researchers have attempted over the last few years to complete the pushover analysis and to overcome the disadvantages of the previous methods. Sasaki et al. (1988) tried to apply the effects of the higher modes of structure on its failure mechanism. By providing the MMP method, they were able to detect the failure mechanism under higher modes, in addition to using the advantages of the pushover method [1]. In 2002, PRC method was presented by Moghadam and Tso. In this method, the effect of higher modes was considered. The structure was covered under different load distributions that were based on different shape modes [2]. In 2002, Chopra and Goel presented a method for calculating the seismic responses of structures. This method was derived from the concepts of multi-mode pushover (MMP) analysis and spectral response analysis, in which the effect 
of higher modes was also considered [3]. Moreover, methods such as Incremental Modal Pushover Analysis (IMPA), Modified Modal Pushover Analysis (MMPA), and evaluation of energy-eased modal pushover analysis have been presented by researchers to improve the pushover method [4-6].

All the studies mentioned here are restricted to two-dimensional frames and three-dimensional symmetric-plan structures. In recent years, researchers have attempted to generalize pushover analysis methods to asymmetric-plan 3D-type building structures for considering torsional effects. The following studies are among the most important ones carried out in this field.

Chopra et al. developed the Modal Pushover Analysis (MPA) method, first, in a regular 3D structure and then, in a structure with irregularity in plan [79]. Poursha et al. developed the consecutive modal pushover procedure first for a structure having irregularity in one direction and then, considering irregularity in both directions [10-12]. Many researches have been conducted to investigate and estimate the behavior of asymmetric-plan buildings (e.g., [13-16]).

All the above-mentioned studies have been devoted to the development of pushover methods. On the other hand, since the Modal Incremental Dynamic Analysis (MIDA) method is a combination of MPA and Incremental Dynamic Analysis (IDA), it is also necessary to express the history of IDA method. Nonlinear IDA, which seems to be the most accurate structural analysis method under earthquake stimulation, was first presented by Bertero in 1977 [17]. Afterwards, many researchers attempted to develop and complete the approach, e.g., Brunesi et al. [18], Zhou et al. [19], and Jalili Sadr Aabad et al. [20]. High accuracy and actual simulation of the behavior of the structure are among the advantages of this method. In this method, the actual nonlinear behavior of the material as well as the actual dynamic nature of the earthquake stimulation is considered. The main method presented as an alternative to the IDA is the MIDA method, which is called MPA-based IDA by some researchers. This method was first presented by Mofid et al. in 2005 [21] and then, it was utilized by Han \& Chopra in 2006 [22]. In 2011, this method was developed by Mofid et al. by means of the trilinear idealization model [23].

This study is aimed at covering a broader range of structures by applying MIDA as a quick and accurate method to steel structures with medium- and relatively-low-rise buildings that are irregular in the plan.

\section{The equation of motion}

As we know, solving the differential equation for a Single-Degree-Of-Freedom (SDOF) structure is simpler and faster than solving the same equation for
Multi-Degree-Of-Freedom (MODF) structures. This issue is most important for doing nonlinear analyses. Thus, the idea of using an SDOF structure with the characteristics of an MDOF structure is a familiar one. Now, the only important issue is to obtain the characteristics of the SDOF structure, including period, damping, yielding load, and stiffness strain. Additionally, the conversion factor for the responses from the SDOF structure to the MDOF structure should be determined.

Since in this study, the structures are modeled in $3 \mathrm{D}$ form, in order to obtain the characteristics of the SDOF structure, the equations of motion are first expressed and then, the MIDA method is interpreted.

In the case of considering $x$ and $y$ components of the motion of the Earth, the equation of motion governing the structure response will be as follows:

$$
M \ddot{u}+f_{s}(u, \operatorname{sign} \dot{u})=-M \iota_{x} \ddot{u}_{g x}(t)-M \iota_{y} \ddot{u}_{g y}(t),
$$

which can also be written in matrix form as follows:

$$
\begin{gathered}
{\left[\begin{array}{ccc}
m & 0 & 0 \\
0 & m & 0 \\
0 & 0 & I_{o}
\end{array}\right]\left\{\begin{array}{l}
\ddot{u}_{x} \\
\ddot{u}_{y} \\
\ddot{u}_{\theta}
\end{array}\right\}+f_{s(u, \operatorname{sign} \dot{u})}} \\
-\left[\begin{array}{ccc}
m & 0 & 0 \\
0 & m & 0 \\
0 & 0 & I_{o}
\end{array}\right] i_{x} \ddot{u}_{g x}(t)-\left[\begin{array}{ccc}
m & 0 & 0 \\
0 & m & 0 \\
0 & 0 & I_{o}
\end{array}\right] i_{y} \ddot{u}_{g y}(t),
\end{gathered}
$$

where, $m$ is a diagonal matrix equal to the lumped mass of each story floor and $I_{o}$ is a mass moment of inertia of each story. $u_{x}$ and $u_{y}$ are the horizontal displacements in $x$ and $y$ directions, respectively, and $u_{\theta}$ is related to the torsional motion of the floor of the structure. The hysteretic and nonlinear forces, $f_{s}$, including $f_{s x}, f_{s y}$, and $f_{s \theta}$, represent the horizontal components of force in $x$ and $y$ directions and torsional force, respectively.

In the governing equation, the effect vector associated with the motion of the Earth along $x$ and $y$ directions is as follows:

$$
\iota_{x}=\left[\begin{array}{l}
1 \\
0 \\
0
\end{array}\right], \quad \iota_{y}=\left[\begin{array}{l}
0 \\
1 \\
0
\end{array}\right] .
$$

The second side of the governing equation can be rewritten as the effective earthquake force, $s \ddot{u}_{g}$, along $x$ and $y$ directions, where $s$ is the spatial distribution of the effective earthquake force:

$$
\mathbf{P}_{\text {eff }}(t)=-\mathbf{s} \ddot{u}_{g}(t)=-\left\{\begin{array}{c}
\mathbf{m} \mathbf{1} \\
0 \\
0
\end{array}\right\} \ddot{u}_{g x}(t), \quad \text { and }
$$

$$
-\left\{\begin{array}{c}
0 \\
\mathbf{m} \mathbf{1} \\
0
\end{array}\right\} \ddot{u}_{g y}(t)
$$




$$
\mathbf{s}=\sum_{n=1}^{3 N} \mathbf{s}_{n}=\sum_{n=1}^{3 N} \Gamma_{n} \mathbf{M} \phi_{n}=\sum_{n=1}^{3 N} \Gamma_{n}\left[\begin{array}{c}
m \phi_{x n} \\
m \phi_{x y} \\
I_{o} \phi_{\theta n}
\end{array}\right]
$$

where, $\phi_{x n}, \phi_{y n}$, and $\phi_{\theta n}$ indicate the modal shapes of the structure vibration in two transitional and torsional directions and:

$$
\Gamma_{n}=\frac{L_{n}}{M_{n}} \quad \mathbf{M}_{n}=\phi_{n}^{T} \mathbf{M} \phi_{n} \quad L_{n}=\left\{\begin{array}{l}
\phi_{n x}^{T} \mathbf{m} \mathbf{1} \\
\phi_{n y}^{T} \mathbf{m} \mathbf{1}
\end{array}\right.
$$

\section{MIDA method}

IDA is capable of well illustrating the demand of structures at different levels of earthquake. Assessing seismic demand under different levels of earthquake by using an approximate approach with sufficient accuracy will save time. In the MIDA method, non-linear dynamic analysis of the MDF structure has not been used to obtain IDA curves so far. To achieve this goal, we first considered the entire structure equivalent to an SDOF one and then, evaluated it through a modal pushover analysis method. Changes can be made in the calculation speed when the analysis of an MDOF structure is not nonlinear dynamic.

The MIDA procedure to estimate the seismic demand of an asymmetric-plan multistory building is a sequence of steps found below:

Step 1. Design and modeling of structures: First, the structures are linearly analyzed and carefully designed. The dynamic properties of the structures, including periods and mode shapes, are obtained in all the three components of $x, y$, and $\theta$.

Step 2. Pushover analysis and obtaining capacity curve of the structures: In order to map an MDOF structure onto SDOF structure, capacity curve of the structure relative to its seismic properties is required. The pushover analysis of the lateral load, $S_{n}^{*}(\mathrm{Eq} \cdot(7))$, is performed for structures in each mode and the base shear-roof displacement curve, which is same as the frame capacity curve, is obtained:

$$
S_{n}^{*}=\left\{\begin{array}{l}
m \phi_{x n} \\
m \phi_{y n} \\
I_{o} \phi_{\theta n}
\end{array}\right\}
$$

Step 3. Idealizing the pushover curve as a bilinear curve: In order to perform an SDOF structural analysis, the force-displacement model is required. Considering software limitations and keeping simplicity of the wok in this method, the force-displacement model should be bilinear. Therefore, the MDOF structure capacity curve in the dominant direction should be approximated by a bilinear model in order to obtain the characteristics of an SDOF structure from it.

Step 4. Obtaining the SDOF system characteristics: To convert the main MDOF structure to an equivalent SDOF structure, it is applied in such a way that the SDOF structure has period and damping equal to the period and damping of the main MDOF structure. Also, its load-deformation curve is obtained from the MDOF structure as shown in Figure 1.

Consequently, the following relationships can be written:

$$
\begin{aligned}
& \frac{F_{s n y}}{L_{n}}=\frac{V_{b n y}}{M_{n}^{*}}, \\
& D_{n y}=\frac{u_{r n y}}{\Gamma_{n} \phi_{r n}},
\end{aligned}
$$

where:

$F_{s n} \quad$ The scaled stiffness of the system proportional to time response of the structure;

$V_{b n}^{y} \quad$ Yielding strength;

$u_{r n}^{y} \quad$ Yielding displacement of the roof of the $i$ th mode of vibration;

$\alpha \quad$ The strain hardening angle of the material;
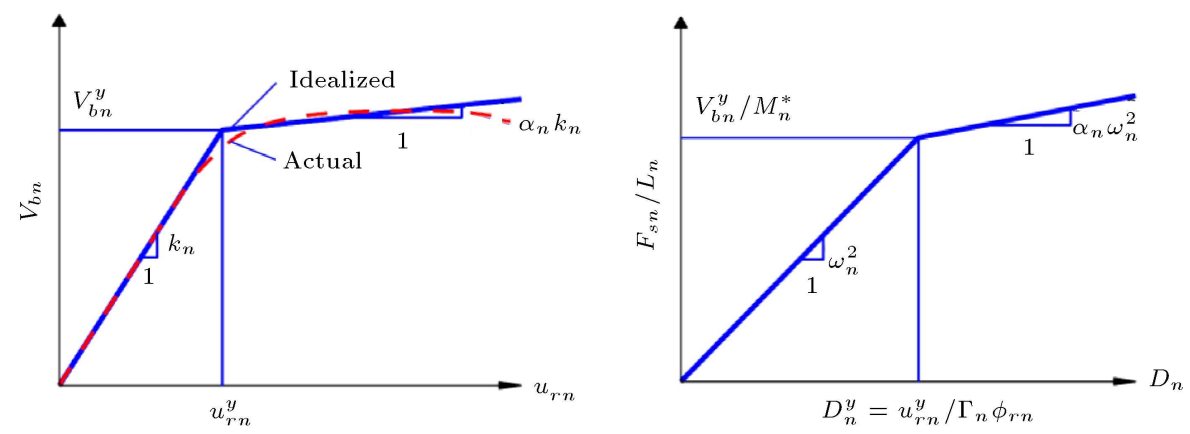

Figure 1. Properties of the $n$ th-mode inelastic SDF system in the pushover curve. 
$\phi_{r n} \quad$ The $\phi_{n}$ at the roof in the direction of the selected pushover curve.

$M_{n}^{*}$ and $\Gamma_{n}$ correspond to the direction of the ground motion under consideration $(x$ or $y$ ) and are equal to:

$$
M_{n}^{*}=\Gamma_{n} L_{n}
$$

Step 5. Analyzing SDOF structure: At this step, the obtained SDOF structure is subjected to the intended earthquake record and nonlinear time-history analysis is performed in order to calculate a maximum displacement $\left(D_{n}\right)$. The SDOF structure acts as a nonlinear spring the force-displacement characteristic of which has been obtained in Step 4.

Step 6. Calculating the maximum displacement of MDOF structure: By multiplying the coefficients $\Gamma_{n y}$ and $\phi_{y n}$ from the displacement obtained in the previous step, the maximum displacement of the MDOF structure will be calculated:

$$
u_{x n}=\Gamma_{n x} \phi_{x n} D_{n} \quad u_{y n}=\Gamma_{n y} \phi_{y n} D_{n} .
$$

Step 7. Performing pushover analysis and extracting the results: The main MDF structure will be pushed, according to $S_{n}^{*}$ lateral loading pattern, to the target displacement $u_{r n}$, which was obtained in the previous step. Then, the maximum drift of each story will be computed for the considered level of scaled earthquake record.

Step 8. Combination of the effects of modes: At the end, the results obtained from different modes should be combined. For this purpose, the maximum roof displacement, the relative story displacement, and the maximum plastic rotation obtained in each mode at the identical seismic level are combined using the SRSS rule.

\section{Modeling and record selection}

The studied structures are 4-, 7-, and 10-story buildings the structural system of which is moment-resisting frame. In addition, the height of each story is $3 \mathrm{~m}$, and the building has 5 spans of $4 \mathrm{~m}$ in the $x$ direction and 3 spans of the same length in the $y$ direction. The $3 \mathrm{D}$ view of the 4-story building is shown in Figure 2.

The structures were primarily designed by assuming linear behavior for the materials, influencing $P-\Delta$ effect, perfectly rigid beam and column connections, and disregarding the dimensions of the panel. The following were also considered in the design:

- The buildings were placed on soil type II;

- The building gravity loading was in accordance with the American standard for loading (ASCE7-10) [24];

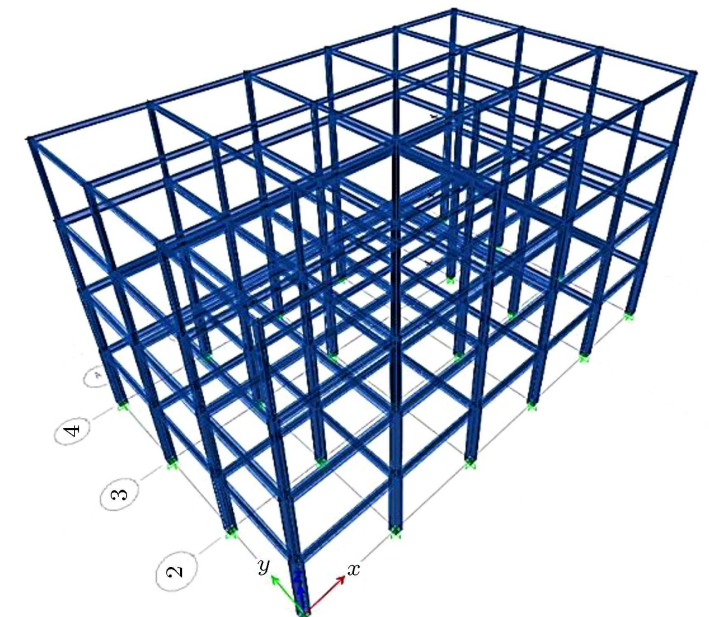

Figure 2. 3D view of the 4-story structure.

- The building lateral loading was according to the American standard for loading (ASCE7-10);

- Designing of the steel members was performed based on American standard for steel structures (AISC360-10) [25].

To create an asymmetry, the story masses were distributed in an unbalanced way so that each story had an eccentricity of $15 \%$ between the centers of gravity and rigidity along the $y$ axis (Figure 3 ).

All nonlinear analyses were performed by Open Sees software (Computers and Structures, 2004).

Scaling acceleration records is one of the most important challenges in nonlinear time history analyses. Different codes and approaches have been proposed for scaling the acceleration records. In this study, the acceleration records were scaled up according to the fourth edition of the Iranian standard no. 2800 (code of practice for earthquake-resistant design of buildings) [26] and noting the considerations suggested by Charney [27]. These three asymmetric-plan buildings would experience coupled $x$-horizontal and torsional motions due to the $x$-component of earthquake, which was the focus of this paper. In this regard, three ground

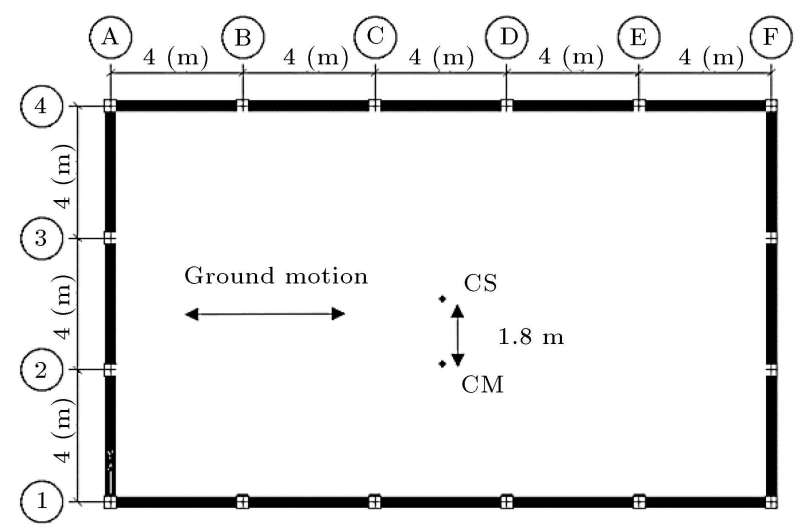

Figure 3. Plan of the selected asymmetric-plan buildings. 

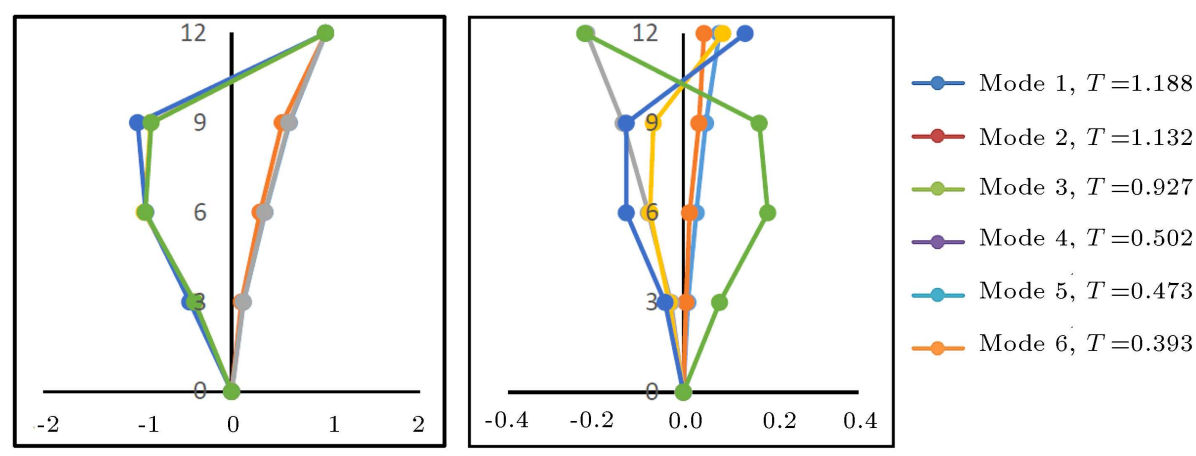

(a)
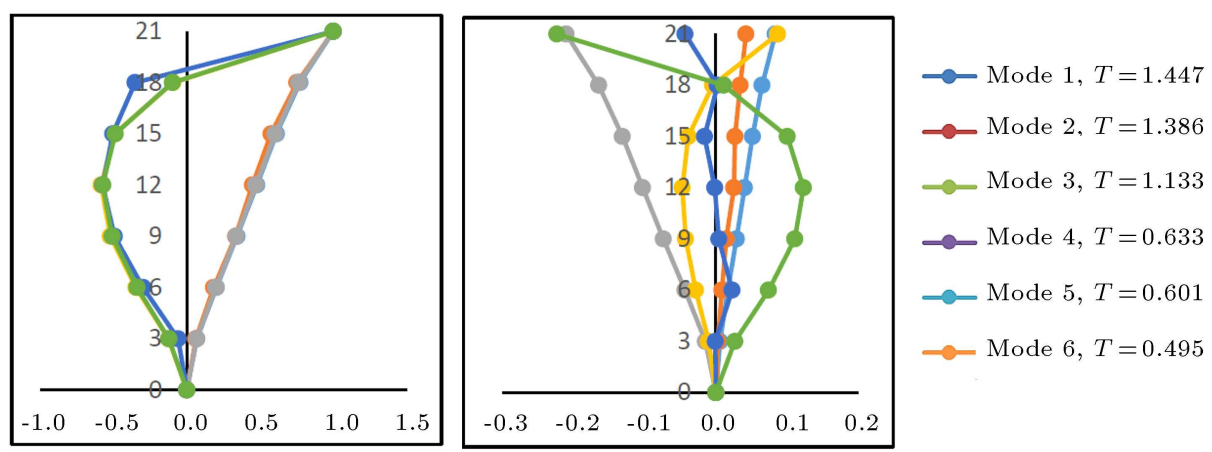

(b)
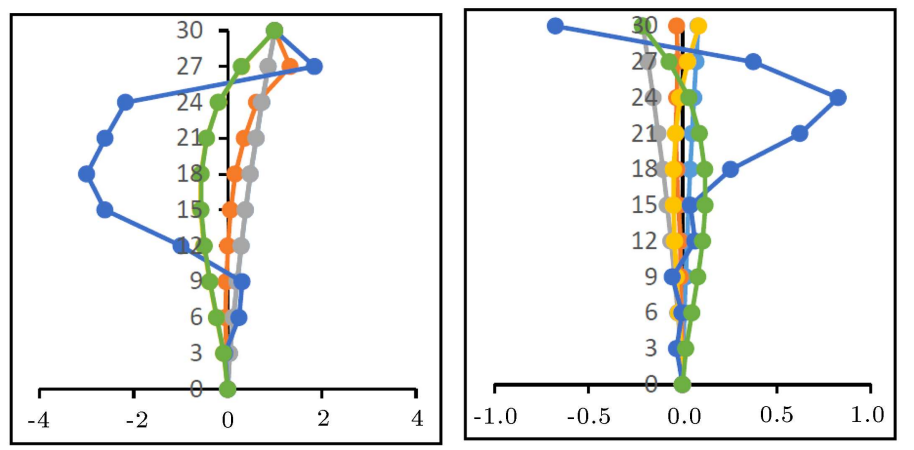

$\multimap$ Mode $1, T=1.654$

$\multimap$ Mode 2, $T=1.596$

- Mode 3, $T=1.296$

$\multimap$ Mode $4, T=0.698$

$\multimap$ - Mode 5, $T=0.666$

$\longrightarrow$ Mode 6, $T=0.547$

(c)

Figure 4. Natural periods and modes of vibration for 4-, 7-, and 10-story asymmetric-plan systems: (a) Asymmetric-plan of 4-story, (b) asymmetric-plan of 7-story, and (c) asymmetric-plan of 10-story.

motion records were used for the time history analysis, including Imperial Valley (1940), Northridge (1994), and Park field (1966).

\section{Numerical results}

After verifying the modeling, the mode shape of each structure was drawn. For this purpose, it was taken from the participation of the first six mods of each structure. Figure 4 illustrates the mode properties of each structure including the natural period of each mode, the horizontal components of $x$-direction, and the torsional component. Having the mode shape and its values, the equations explained in detail in the previous section were solved.
Thereafter, the structures were pushed with regard to force distribution, $S_{n}^{*}$, to obtain the base shear curves based on the roof displacement and then, the curves were idealized with bilinear curves. The pushover curves for the four modes of the 10story building, where $x$ component of displacements is dominant compared to the $y$ component, are shown in Figure 5.

Figures 6,7 , and 8 compare the MIDA and the exact IDA for 4-, 7-, and 10-storey buildings with three ground motion records, respectively. Each figure is presented for maximum inter-story drift.

In order to estimate the seismic demand, the contribution of the first six modes was included in the analysis of the asymmetric building. As expected, the 

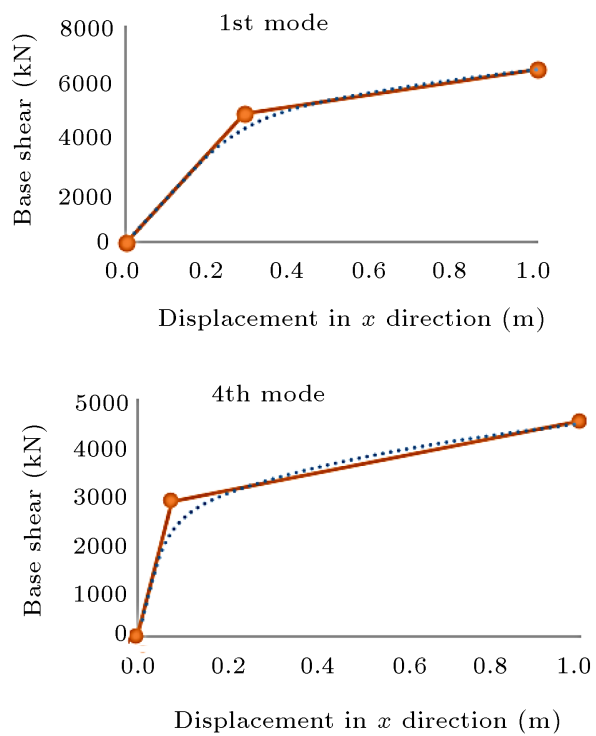
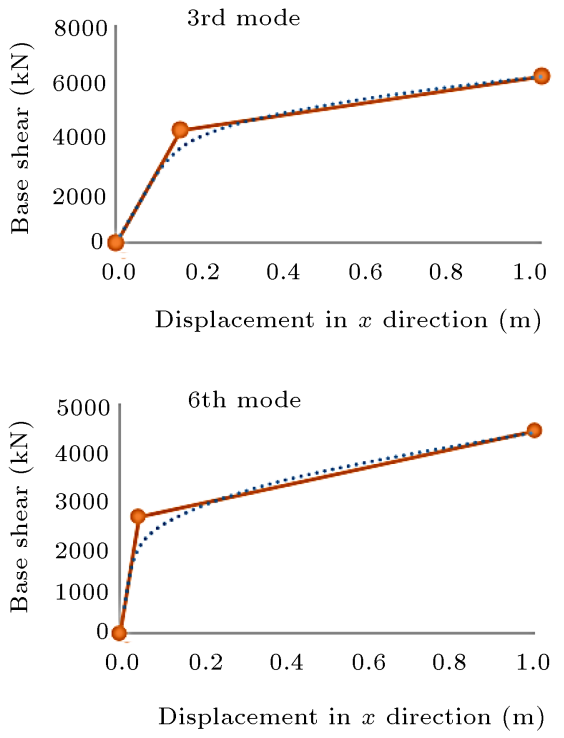

Figure 5. Bilinear idealization of the pushover curve for the 10-story building.
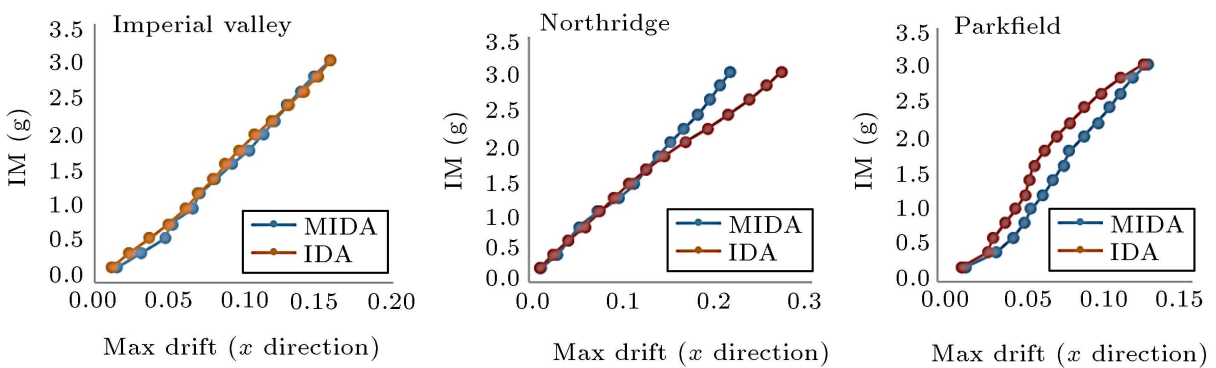

Figure 6. Comparing the single IDA and MIDA curves for maximum inter-story drift with three records for the 4-story building.
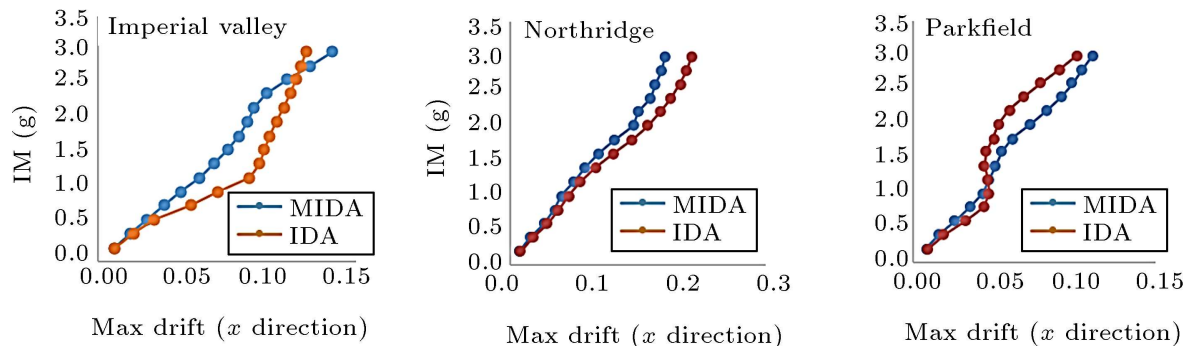

Max drift ( $x$ direction)

Max drift ( $x$ direction)

Figure 7. Comparing the single IDA and MIDA curves for maximum inter-story drift with three records for the 7-story building.

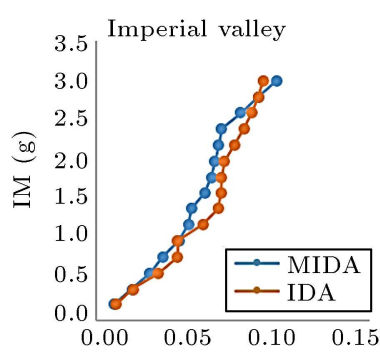

Max drift ( $x$ direction)

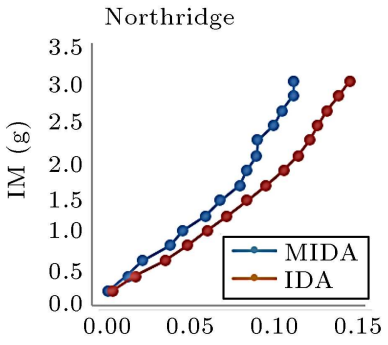

Max drift ( $x$ direction)

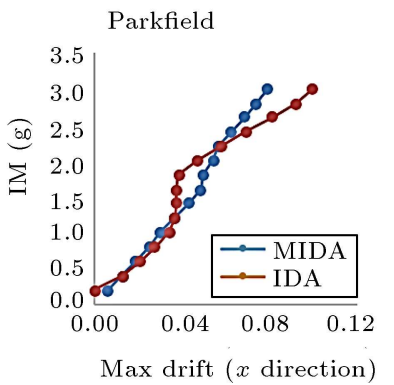

Figure 8. Comparing the single IDA and MIDA curves for maximum inter-story drift with three records for the 10-story building. 

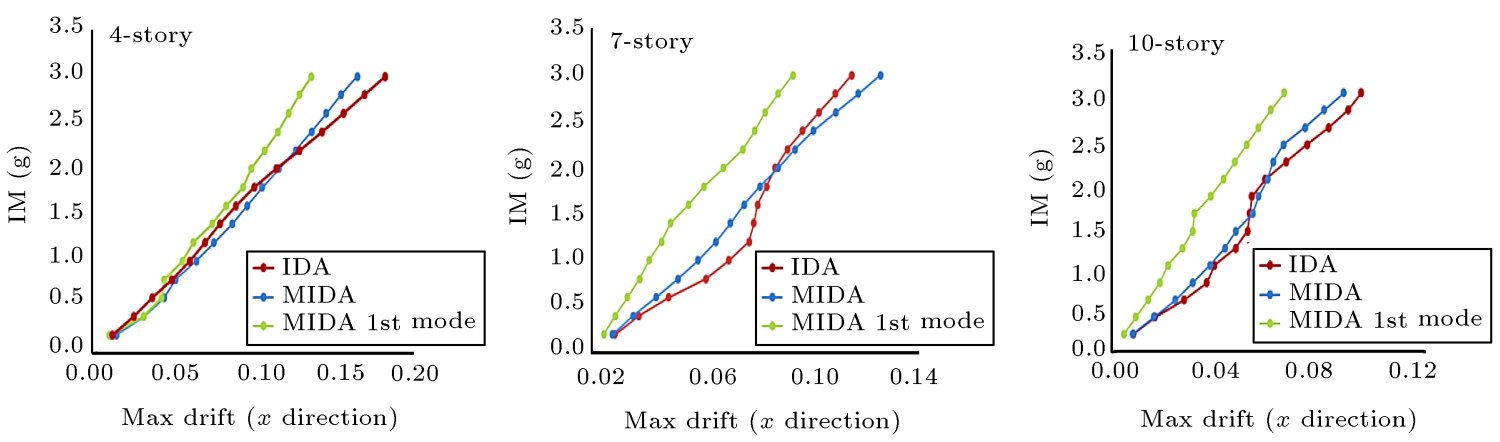

Figure 9. Influence of higher modes on the accuracy of MIDA method.

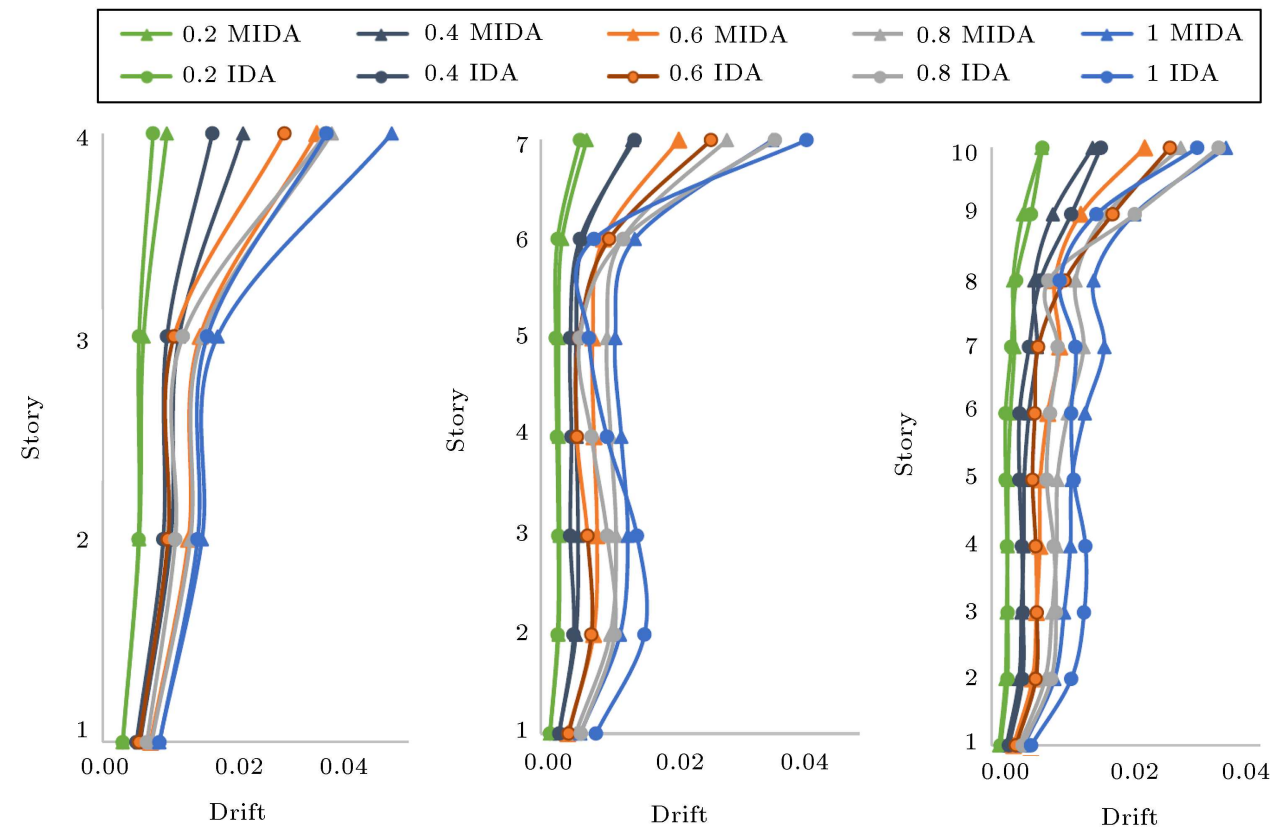

Figure 10. Story drifts at CM for the first five steps of Imperial Valley earthquake.

first mode had an insignificant impact in estimating the story drifts, especially in the upper step of the earthquake (Figure 9). Also, considering the response contribution of higher modes significantly enhanced the story drifts. For checking the precision of this method, story drifts at CM for Imperial Valley earthquake are displayed in Figure 10 only for maximum displacement.

\section{Conclusion}

The purpose of present study is to extend the Modal Incremental Dynamic Analysis (MIDA) method for 3D structures with irregularity in plan. Performance of the MIDA procedure has been investigated on three moment-resisting structure with 4,7 , and 10 stories. Seismic responses from MIDA procedure have been compared with those from IDA method.

- From the single and multiple curves of IDA and MIDA as well as their difference percentages, it was found that the MIDA method was capable of correctly assessing the behavior of the structure with an error not exceeding 15\%;

- The error of MIDA method at lower levels of earthquake intensity was much lower and the difference between the two diagrams increased by increasing earthquake intensity. This was due to the nonlinear behavior of the structure in higher earthquake intensities. In fact, in smaller scale factors, since the structure was in the linear region, the accuracy of the MIDA method was greater and the method was more consistent with the results of IDA. However, by increasing the earthquake intensity, the structure began to leave the linear region and move towards the nonlinear region. Moreover, this nonlinear behavior led to approximations in the work. Therefore, as the intensity of the earthquake increased and more structural elements entered the nonlinear region, inaccuracy of the MIDA approach 
increased. However, it was still accurate enough in high-intensity earthquakes;

- The difference between the MIDA and IDA diagrams in the 4-story structure was very small; however, the greater the number of stories, the greater the difference would be. The reason was that the effect of higher modes, especially the torsional modes, increased with increase in the number of stories. Also, inaccuracy of MIDA increased;

- In the analysis of 3D structures using the MIDA method, solely the first mode of a structure cannot give us its correct response. Therefore, in such structures, the effect of higher modes should be considered. We used the first six modes in the present study;

- The most important issue to note is that using an MDF systems to perform dynamic analysis (IDA method) is very time-consuming. This issue is intensified with a steep slope with increase in the number of stories, while the time demanded by the MIDA method for the analysis of a structure is considerably low in comparison. For instance, the computation time required for 4-storey buildings is reduced from two days for an accurate result to only two hours for the approximate result.

\section{References}

1. Sasaki, K.K., Freeman, S.A., and Paret, T.F. "Multimode pushover procedure (MMP)-A method to identify the effects of higher modes in a pushover analysis", Proceedings of the 6th US National Conference on Earthquake Engineering, 620(10), Seattle, Washington (1998).

2. Moghadam, A.S. and Tso, W.K. "A pushover procedure for tall buildings", Proc. of the Twelfth European Conference on Earthquake Engineering, London, United Kingdom, Paper. No. 395 (2002).

3. Chopra, A.K. and Goel, R.K. "A modal pushover analysis procedure for estimating seismic demands for buildings", Earthquake Engineering \& Structural Dynamics, 31(3), pp. 561-582 (2002).

4. Bergami, A.V., Forte, A., Lavorato, D., and Nuti, C. "Proposal of a incremental modal pushover analysis (IMPA)", Earthq. Struct, 13, pp. 539-549 (2017).

5. Pan, X., Zheng, Z., and Wang, Z. "Estimation of floor response spectra using modified modal pushover analysis", Soil Dynamics and Earthquake Engineering, 92, pp. 472-487 (2017).

6. Hashemi, M.J. and Mofid, M. "Evaluation of energybased modal pushover analysis in reinforced concrete frames with elevation irregularity", Scientia Iranica. Transaction A, Civil Engineering, 17(2), pp. 96-106 (2010).

7. Chopra, A.K. and Goel, R.K. "A modal pushover analysis procedure to estimate seismic demands for unsymmetric-plan buildings", Earthquake Engineering \& Structural Dynamics, 33(8), pp. 903-927 (2004).

8. Reyes, J.C. and Chopra, A.K. "Three-dimensional modal pushover analysis of buildings subjected to two components of ground motion, including its evaluation for tall buildings", Earthquake Engineering \& Structural Dynamics , 40(7), pp. 789-806 (2011).

9. Reyes, J.C. and Chopra, A.K. "Evaluation of threedimensional modal pushover analysis for unsymmetricplan buildings subjected to two components of ground motion", Earthquake Engineering \& Structural Dynamics, 40(13), pp. 1475-1494 (2011).

10. Poursha, M., Khoshnoudian, F., and Moghadam, A.S. "A consecutive modal pushover procedure for nonlinear static analysis of one-way unsymmetric-plan tall building structures", Engineering Structures, 33(9), pp. 2417-2434 (2011).

11. Poursha, M., Khoshnoudian, F., and Moghadam, A.S. "The extended consecutive modal pushover procedure for estimating the seismic demands of two-way unsymmetric-plan tall buildings under influence of two horizontal components of ground motions", Soil Dynamics and Earthquake Engineering, 63, pp. 162173 (2014).

12. Poursha, M. and Samarin, E.T. "The modified and extended upper-bound (UB) pushover method for the multi-mode pushover analysis of unsymmetric-plan tall buildings", Soil Dynamics and Earthquake Engineering, 71, pp. 114-127 (2015).

13. Reyes, J.C., Riaño, A.C., Kalkan, E., and Arango, C.M. "Extending modal pushover-based scaling procedure for nonlinear response history analysis of multistory unsymmetric-plan buildings", Engineering Structures, 88, pp. 125-137 (2015).

14. Tarbali, K. and Shakeri, K. "Story shear and torsional moment-based pushover procedure for asymmetricplan buildings using an adaptive capacity spectrum method", Engineering Structures, 79, pp. 32-44 (2014).

15. Belejo, A. and Bento, R. "Improved modal pushover analysis in seismic assessment of asymmetric plan buildings under the influence of one and two horizontal components of ground motions", Soil Dynamics and Earthquake Engineering, 87, pp. 1-15 (2016).

16. Soleimani, S., Aziminejad, A., and Moghadam, A.S. "Extending the concept of energy-based pushover analysis to assess seismic demands of asymmetric-plan buildings", Soil Dynamics and Earthquake Engineering, 93, pp. 29-41 (2017).

17. Bertero, V.V. "Strength and deformation capacities of buildings under extreme environments", Structural Engineering and Structural Mechanics, 53(1), pp. 2979 (1977).

18. Brunesi, E., Nascimbene, R., Parisi, F., and Augenti, N. "Progressive collapse fragility of reinforced concrete framed structures through incremental dynamic analysis", Engineering Structures, 104, pp. 65-79 (2015). 
19. Zhou, Y., Ge, P., Li, M., and Han, J. "An areabased intensity measure for incremental dynamic analysis under two-dimensional ground motion input", The Structural Design of Tall and Special Buildings, 26(12), p. e1374 (2017).

20. Jalili Sadr Abad, M., Mahmoudi, M., and Dowell, E. "Novel technique for dynamic analysis of shear-frames based on energy balance equations", Scientia Iranica (2018) (In press). DOI: 10.24200/sci.2018.20790

21. Mofid, M., Zarfam, P., and Fard, B.R. "On the modal incremental dynamic analysis", The Structural Design of Tall and Special Buildings, 14(4), pp. 315329 (2005).

22. Han, S.W. and Chopra, A.K. "Approximate incremental dynamic analysis using the modal pushover analysis procedure", Earthquake Engineering \& Structural Dynamics, 35(15), pp. 1853-1873 (2006).

23. Zarfam, P. and Mofid, M. "On the modal incremental dynamic analysis of reinforced concrete structures, using a trilinear idealization model", Engineering Structures, 33(4), pp. 1117-1122 (2011).

24. ASCE/SEI 7-10, Minimum Design Loads for Buildings and Other Structures, American Society of Civil Engineers (2010).
25. AISC Committee, Specification for Structural Steel Buildings (ANSI/AISC 360-10), American Institute of Steel Construction, Chicago-Illinois (2010).

26. Standard No. 2800-05, Iranian Code of Practice for Seismic Resistant Design of Buildings, 4th Edition, Iran Building and Housing Research Centre; (2014).

27. Charney, F.A., Seismic Loads: Guide to the Seismic Load Provisions of ASCE 7-10, American Society of Civil Engineers (2015).

\section{Biographies}

Moein Zanjanchi completed his MSc studies at Sharif University of Technology in 2016. His research interests are in the areas of structural dynamics and earthquake engineering, seismic design of steel and concrete structures, finite element analysis, and rehabilitation.

Massood Mofid is a Professor in the Civil Engineering Department at Sharif University of Technology. He completed his PhD studies at Rice University. 